\title{
Systemic and Intralesional Bevacizumab in Juvenile Onset Recurrent Respiratory Papillomatosis: A Report of Two Cases
}

\author{
Arun Goyal $^{1} \cdot$ Dhruv Kapoor $^{1}$ (D) $\cdot$ Richa Saha $^{1}$
}

Received: 11 December 2020/Accepted: 8 August 2021/Published online: 18 August 2021

(C) Association of Otolaryngologists of India 2021

\begin{abstract}
Recurrent respiratory papillomatosis (RRP) is a stubborn disease. Despite volumes of researches done for a definite cause and management, the scientific community offers only theories for causation and options for treatments. Bevacizumab has emerged as a promising solution to the fear of sufferers of RRP of undergoing repeated surgeries. The patients who received bevacizumab, either systemically or intralesionally, show decreased need for surgeries mostly and even remission in a few. Till date there are limited studies of use of bevacizumab, in adults, but only reports of its use in pediatric population. This is a report of two cases of juvenile onset RRP with use of systemic bevacizumab infusion in a child and intralesional injection in an adult.
\end{abstract}

Keywords Recurrent respiratory papillomatosis .

Bevacizumab · JORRP · Adjuvant treatment .

Medical treatment

Dhruv Kapoor

dkapooralld@gmail.com

Arun Goyal

arungoyal150@yahoo.co.in

Richa Saha

richadrsaha@gmail.com

1 Department of Otorhinolaryngology, University College of Medical Sciences, Ward 25, UCMS and GTB Hospital, Dilshad Garden, Delhi 110095, India

\section{Introduction}

Recurrent respiratory papillomatosis (RRP) is a rare but frustrating disease both for the patient and treating otolaryngologist. The fear of the patient of succumbing to respiratory distress anytime and being subjected to multiple procedures is as disturbing as the thought of the doctor of repeatedly operating on the same patient without completely curing the disease.

After discovery of evidence for increased angiogenic activity in the excised RRP histopathological specimen, bevacizumab, a biological agent, an antagonist of vascular endothelial growth factor (VEGF), was identified as a potential treatment modality [1]. Local bevacizumab injections, has shown promising results in porcine laryngeal models, and shown satisfactory results as an adjuvant treatment in adult onset RRP [2-4]. But there have only been few case reports of its use in paediatric age group [5].

This is a report of experience of a tertiary care centre in Delhi, India on management of two cases of juvenile onset RRP with systemic administration of bevacizumab in a child and local injection in an adult.

\section{Case 1}

A 4-year old girl first presented in 2018 as an out-patient with a history of hoarseness of voice for 3 months. She underwent laryngeal papilloma ablation using $\mathrm{CO}_{2}$ laser. Initially the need for surgeries were nearly 3-4 monthly in 2018 when the papillomas were limited only till larynx. During the course she underwent a tracheotomy due to excessive respiratory distress and required surgery nearly every 30-45 days in 2019 during which the extent increased till tracheotomy site, lower trachea and carina. 
Adjuvant treatment with systemic bevacizumab infusion was planned and was given 3 weekly at a dose of $10 \mathrm{mg} / \mathrm{kg}$ body weight. She underwent a repeat evaluation after 3 months after receiving 4 doses. She also received three doses of HPV vaccine Cervarix ${ }^{\circledR}$. Derkay score were documented at 3 stages (Table 1): in 2018 when she was first diagnosed (Derkay score 15); before start of systemic bevacizumab administration (Derkay score 26) and after receiving 4 doses of systemic bevacizumab (Derkay score 8). Further doses were postponed because of the COVID 19 outbreak. After 3 months of discontinuing the infusion, the child developed difficulty in breathing with corked tracheostomy tube, and is presently unable to tolerate corking of tracheostomy tube.

\section{Case 2}

An 8-year female presented to the out-patient at a tertiary care centre in 2003 with change in voice and on evaluation was found to have laryngeal papilloma for which she underwent surgery. In 2019, now aged 24 years, she presented at our centre with hoarseness of voice and required a second surgery for laryngeal papilloma and anterior web. (Fig. 1) Next requirement of surgery arrived after 4 months. Figure 2 shows the post-operative endoscopic picture of larynx. She was taken up for adjuvant treatment with local bevacizumab injection. Bevacizumab was injected locally twice at 2 weeks interval. Figure 3 shows the status of larynx after 2 doses of local bevacizumab injection. She also received 3 doses of Gardasil ${ }^{\circledR}$ vaccine. The next bevacizumab doses were postponed due to the COVID 19 outbreak. She is, at the time of writing this report, normal with no complaint of change in voice or respiratory distress.

\section{Discussion}

Caused mostly by HPV 6 and 11, RRP can be life threatening both in its benign form by narrowing the airway by mass effect, as well as in its pre-malignant potential. The classical modality of treatment is surgical debridement using cold instrumentation, carbon dioxide laser or

Table 1 Derkay scores of Case 1 showing the extent of disease at the time of diagnosis, before start of systemic bevacizumab infusions and after 4 doses

\begin{tabular}{|c|c|c|c|}
\hline Site & $\begin{array}{l}\text { Score at time of } \\
\text { diagnosis }\end{array}$ & $\begin{array}{l}\text { Score before bevacizumab } \\
\text { infusion }\end{array}$ & $\begin{array}{l}\text { Score after } 4 \text { doses of systemic } \\
\text { bevacizumab infusion }\end{array}$ \\
\hline Epiglottis_-lingual surface & 0 & 0 & 0 \\
\hline Epiglottis-laryngeal surface & 0 & 0 & 0 \\
\hline Right aryepiglottic fold & 0 & 0 & 0 \\
\hline Left aryepiglottic fold & 0 & 3 & 0 \\
\hline Right false vocal cord & 3 & 2 & 0 \\
\hline Left false vocal cord & 3 & 3 & 0 \\
\hline Right true vocal cord & 3 & 3 & 0 \\
\hline Left true vocal cord & 3 & 3 & 0 \\
\hline Right arytenoid & 0 & 0 & 0 \\
\hline Left arytenoid & 0 & 0 & 0 \\
\hline Anterior commissure & 3 & 3 & 0 \\
\hline Posterior commissure & 0 & 0 & 0 \\
\hline Subglottis & 0 & 2 & 0 \\
\hline Trachea-upper one-third & 0 & 2 & 2 \\
\hline Trachea-middle one-third & 0 & 1 & 1 \\
\hline Trachea-lower one-third & 0 & 1 & 1 \\
\hline Right bronchus & 0 & 0 & 1 \\
\hline Left bronchus & 0 & 0 & 0 \\
\hline Tracheotomy stoma & 0 & 3 & 3 \\
\hline $\begin{array}{l}\text { Other sites (nose, palate, pharynx, oesophagus, } \\
\text { lungs, others) }\end{array}$ & 0 & 0 & 0 \\
\hline Total score & 15 & 26 & 8 \\
\hline
\end{tabular}

For each site scoring is done as: 0=None; 1=Surface lesion; 2=Raised Lesion; 3=Bulky lesion 


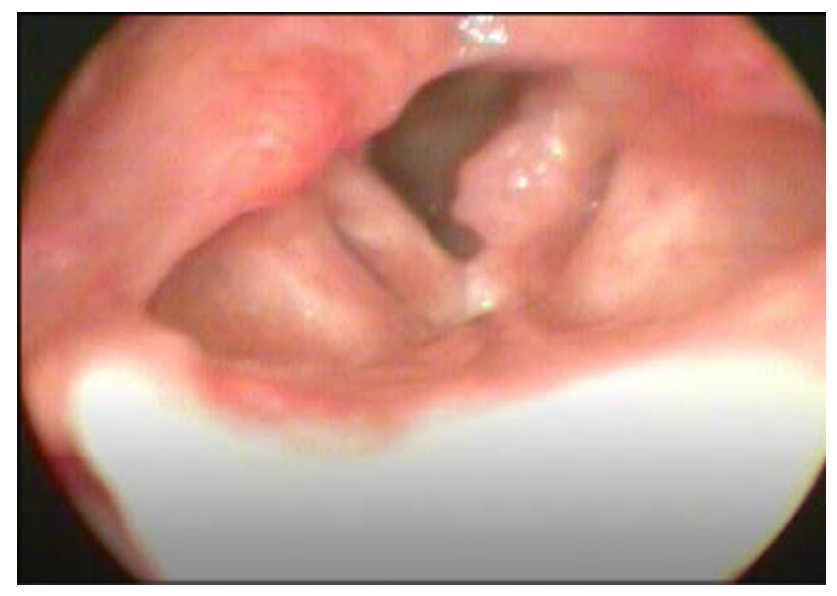

Fig. 1 Case 2-Endoscopic view of larynx showing papilloma on left true vocal cord and anterior web

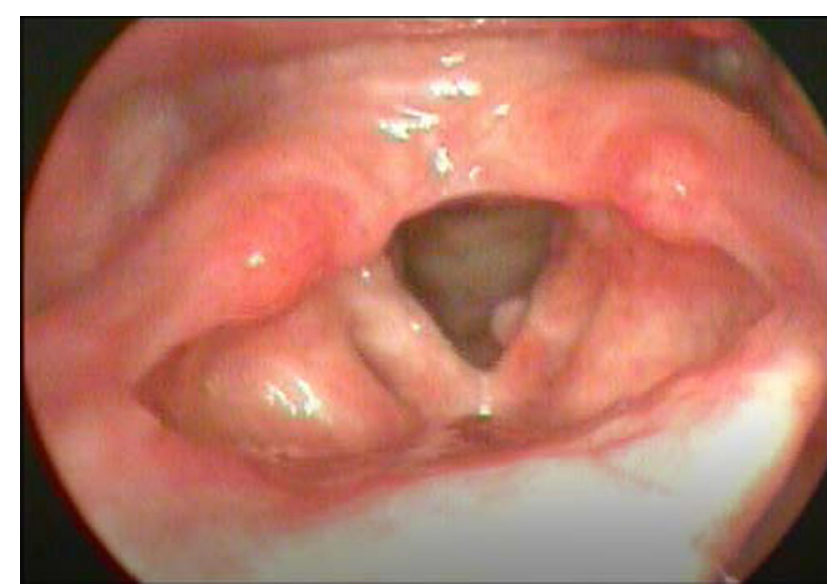

Fig. 2 Case 2-Endoscopic picture of the larynx 2 weeks after the third surgery showing post-operative inflammatory changes over left TVC with papilloma on under surface of left TVC

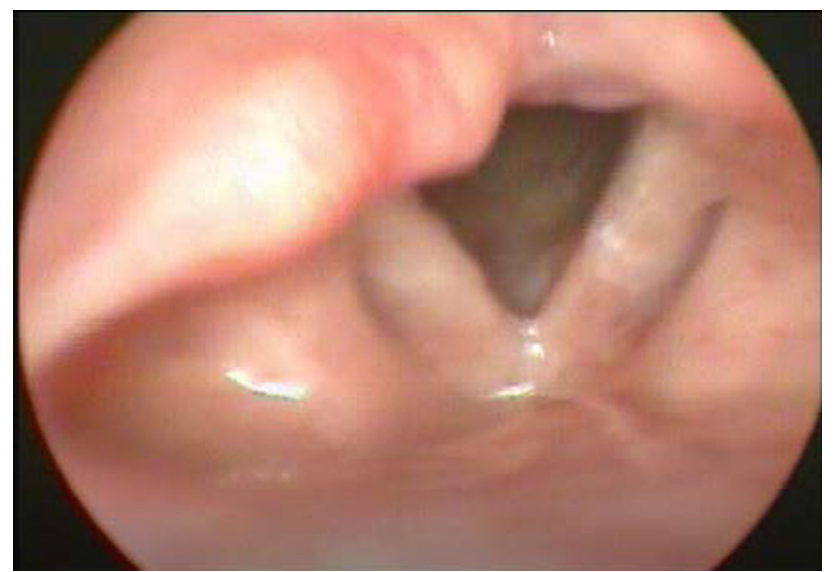

Fig. 3 Case 2-Endoscopic picture of larynx after 2 doses of intralesional bevacizumab injection showing resolution of papilloma with residual mild irregularity of right TVC microdebrider. The adjuvant treatments are advocated in those cases where multiple surgeries, generally more than 6 in a year, are required with decreased interval between two surgeries, or in cases with pulmonary involvement.

Cidofovir (both intralesional and systemic administration) has been the most widely used adjuvant therapy for the disease, off-label [6, 7]. Nonetheless, no specific treatment is very promising. Bevacizumab, a VEGF antagonist, is an anti-angiogenic agent which was first considered a modality of adjuvant therapy when evidence of strong expression of VEGF-A messenger RNA was found on the epithelium of laryngeal papilloma on in situ hybridisation, along with increased expression of VEGF receptors 1 and 2 (VEGFR-1 and VEGFR-2) in underlying vascular endothelial cells [1].

Local injections of bevacizumab have been postulated to increase the concentration of anti-VEGF to act locally. Prior use of systemic infusions of treatment of other malignancies as colon, breast and gliomas, laid basis for trying it in cases of refractory RRP. However, both routes of administration of bevacizumab, have shown beneficial effect in increasing the interval between surgeries and in a few patients, as well as resolution of the lesions. It has improved the voice outcome of the patient as well. But the studies have been conducted on adult onset RRP and adults with juvenile onset RRP [8]. While local injections are not reported to have any systemic complications, systemic infusions of the drug is known to cause self-limiting proteinuria, haemoptysis, hypertension, joint pain and lethargy which mostly improve with cessation of therapy or by increasing duration between doses. Other life threatening but relatively rare complications include intracranial haemorrhages, thromboembolism, hypertensive crisis and gastrointestinal perforations have also been reported, but more in adults than children [9]. Other available options for adjuvant therapy are indole-3-carbinol and interferon- $\alpha 2 \mathrm{a}$, celecoxib, and vaccination for HPV.

Although the use of bevacizumab for RRP has increased but, lack of strong evidence in literature requires larger multicentric trials to assess efficacy of systemic and intralesional bevacizumab administration in both paediatric and adult population, and prospective studies for studying the long-term effects of bevacizumab.

\section{Declarations}

Conflict of interest The authors declare that they have no conflict of interest.

Ethical Approval Since this is a case report ethical approval was not.

Consent for Publication Informed consent for publication was taken from the parents of the child and the adult patient herself. 
Informed Consent of the Patient's Guardian It was provided by parents of the child and from the adult patient herself.

\section{References}

1. Vargas SO, Healy GB, Rahbar R, Folkman J, Tan X, McGill TJ, et al. (2005) Role of vascular endothelial growth factor-a in recurrent respiratory papillomatosis. Ann Otol Rhinol Laryngol. 114(4):289-295. Available from: https://pubmed.ncbi.nlm. nih.gov/15895784/

2. Best SR, Mohr M, Zur KB. (2017) Systemic bevacizumab for recurrent respiratory papillomatosis: a national survey. Laryngoscope. 127(10):2225-2229. Available from: http://doi.wiley. com/10.1002/lary.26662

3. Bedoya A, Glisinski K, Clarke J, Lind RN, Buckley CE, Shofer S. (2017) Systemic bevacizumab for recurrent respiratory papillomatosis: a single center experience of two cases. Am J Case Rep. 18:842-846. Available from: http://www.amjcaserep.com/ abstract/index/idArt/904416

4. Fernandez-Bussy S, Labarca G, Vial MR, Soto R, Mehta HJ, Jantz M, et al. (2018) Recurrent respiratory papillomatosis and bevacizumab treatment. Am J Respir Crit Care Med. American Thoracic Society; 197:539-541. Available from: http://www. atsjournals.org/doi/10.1164/rccm.201702-0279LE

5. Zur KB, Fox E (2017) Bevacizumab chemotherapy for management of pulmonary and laryngotracheal papillomatosis in a child.
Laryngosc. John Wiley and Sons Inc.; 127:1538-1542. Available from: http://doi.wiley.com/10.1002/lary.26450

6. Schroff S, Derkay CS, Burke B, Lawson L. (2004) American Society of Pediatric Otolaryngology members' experience with recurrent respiratory papillomatosis and the use of adjuvant therapy. Arch Otolaryngol Head Neck Surg 130(9):1039-42. Available from: https://pubmed.ncbi.nlm.nih.gov/15381589/

7. Derkay CS, Volsky PG, Rosen CA, Pransky SM, McMurray JS, Chadha NK, et al. (2013) Current use of intralesional cidofovir for recurrent respiratory papillomatosis. Laryngoscope. 123(3):705-12. Available from: https://pubmed.ncbi. nlm.nih.gov/23070868/

8. Drejet S, Halum S, Brigger M, Skopelja E, Parker NP. (2017) A systematic review: outcomes in adult recurrent respiratory papillomatosis treated with intralesional cidofovir or bevacizumab. Otolaryngol Head Neck Surg (United States). 6(3):435-41. Available from: http://journals.sagepub.com/doi/10.1177/ 0194599816683384

9. Hwang EI, Jakacki RI, Fisher MJ, Kilburn LB, Horn M, Vezina G, et al. (2013) Long-term efficacy and toxicity of bevacizumabbased therapy in children with recurrent low-grade gliomas. Pediatr Blood Cancer. 60(5):776-82. Available from: http://doi.wiley.com/10.1002/pbc.24297

Publisher's Note Springer Nature remains neutral with regard to jurisdictional claims in published maps and institutional affiliations. 